\title{
53.090 Virtual Rusks $=$ 510 Real Smiles Using a Fun Exergame Installation for Advertising Traditional Food Products
}

\author{
Dimitris Grammenos, George Margetis, \\ Panagiotis Koutlemanis, and Xenophon Zabulis \\ Foundation for Research and Technology - Hellas (FORTH), Institute of Computer Science \\ \{gramenos, gmarget, koutle, zabulis\} aics.forth.gr
}

\begin{abstract}
This paper presents an innovative advergame installation for promoting the brand and products of a company producing Cretan rusks. The paper first presents some background and related work. Then, the requirements set towards creating the game are outlined, followed by concept creation and design decisions taken to meet these requirements, as well as a description of the user interface, gameplay and technical characteristics of the resulting game. The game has been installed with remarkable success in two different food exhibitions in key locations in Athens, Greece, where it has been played by more than 500 people of ages ranging from 2 to 76 years old. A large variety of qualitative and quantitative data were collected. The paper presents several findings stemming from these data. Additionally, changes made to the game as a result of the findings are presented, along with lessons learnt from the acquired experience.
\end{abstract}

Keywords: Advergames, marketing, game design, public interactive installation, experience design, casual games, serious games.

\section{Introduction}

Typically, the promotion of products in food exhibitions and points of sale is performed through the dissemination of paper material such as posters and leaflets, as well as through tasting and dispensing of free samples. Sometimes, simple audiovisual means like videos, and / or rolling presentations are additionally used. Admittedly, this approach has several drawbacks:

1. It is passive. Potential clients are mere recipients of information. Thus, it is left to their personal initiative to get (further) interested in the advertised products.

2. Everybody does it. Especially in large exhibitions, there is little differentiation among exhibitors, making it very difficult to stand out from the crowd.

3. The time that each visitor is 'exposed' to a brand and its products is minimal.

4. Recollecting which product was made by which company may be particularly hard after one has seen or tasted several products of the same type.

5. It can quickly become tiring and boring. 
In the past few years, a trend towards more active, user-involving marketing of products has surfaced, through the use of interactive games purposefully designed for a specific brand. This trend is commonly referred to as advergaming [19] (from "advertising" and "gaming"). Most existing advergames are targeted to personal computers (e.g., downloadable or Web-based programs [3]), game consoles [19] and mobile devices. Still, large multinational brands such as BMW [11], Goodyear [6], Coca Cola [21], etc., often employ advergames as a means of enhancing their "outdoor advertising" campaigns, i.e., advertising that reaches consumers while they are outside their homes. In this context, this paper presents the concept creation, experience design, software development and user-based assessment of an advergame installation that was developed by the Institute of Computer Science of the Foundation for Research \& Technology - Hellas (ICS-FORTH). The game is targeted to promoting, in exhibition spaces and key points of sale, the brand and products of "Kriton Artos", , a company producing traditional Cretan rusks.

\section{Background and Related Work}

Product placement or, in-game advertisement (IGA), in video games started since the early 1980s [19]. At about the same time, advergames also appeared [19] representing a more dynamic marketing approach, eventually blurring the lines between entertainment and persuasion [3]. Up to now, advergame research has mainly focused on online / web-based games, primarily targeting children and young(er) adults $[3 ; 25]$. According to eMarketer [5] display ads, advergames and advertising on web-based game portals are the leading game-related ad segments in the US. By 2013, the worldwide social game ad market is expected to reach $\$ 641$ million. In the past few years there has been an increasing interest in analyzing and testing several aspects of advergames. In this context, related findings [e.g., 9; 25] support that congruity between the brand and the content of the game impacts brand memory and attitudes towards the game. Congruity can be assessed across a number of dimensions, including [14] function, lifestyle, image and advertising. Evidently, there is a fine balance in the level of game-product congruity, since too little congruity may result is inferior memory effects, while, according to the Persuasion Knowledge Model [7], too much may raise mental barriers against the communicated message.

Several papers [e.g., $2 ; 10 ; 20 ; 22]$ reference, analyze or contribute towards attaining the "holy grail" of (adver)games - the feeling of flow (or optimal experience). The term was originally introduced by Csikszentmihalyi [1] regarding rewarding everyday life and work activities in which people are highly involved. A key element for achieving flow is a perfect balance between one's skills and a task's challenge. Experiments by Waiguny et al [23] and Gurau [10] confirmed that an optimal challenge flow state can positively influence brand evaluations in advergames and the buying behavior of players. Based on flow theory, there have been several attempts $[2 ; 10$; 22] to develop theoretical frameworks for inducing flow within games, also mapping

www.kritonartos.gr 
the 8 original flow elements specified by Csikszentmihalyi to respective gameplay elements. Overall, research findings converge towards the fact that advergames are an effective tool for achieving brand awareness $[9 ; 10 ; 12 ; 23 ; 25]$ and that they have a clear advantage over past approaches [24]. Furthermore, there is evidence that if a game is entertaining, it has a positive influence on brand marketing due to emotional conditioning $[10 ; 23]$, where the enjoyable gaming experience is combined with a specific brand, and subconsciously recollected in future situations. An interesting fact is that prior game-playing experience does not seem to relate to advergame brand memory $[9 ; 18 ; 24]$. Additionally, there is some indication that players who perform well within the game environment tend to retain in-game advertising messages better than players who perform badly [8]. Another important fact is that players who are aware of the presence of in-game advertising are statistically more likely to be happy with its use [12]. A discussion of the vast literature regarding the design of successful games is beyond the scope of this paper. There has been some work specifically targeted to advergames, such as a list of characteristics of a successful advergame defined by companies specialized in this genre [10], and O'Green's [17] "Top things NOT to do in advergaming".

A key differentiating factor of the presented work over previous efforts is that, up to now, although a number of public advergame installations have been developed, neither related design information, nor qualitative or quantitative assessment data have been published.

\section{Game Design}

After conducting several meetings with representatives of the food company, a set of goals that the target game should meet were agreed. More specifically, it should:

1. Allow the broader public to learn about, recognize and remember the brand's name and products and establish a positive image about them.

2. Link the brand and its products with the island of Crete, reinforcing the fact that they are locally-made and traditional.

3. Inform about potential uses of the products.

4. Establish a mental connection between the products and notions such as exercise, healthy living, positive energy, having fun.

5. Provide an opportunity for rewarding active visitor participation (e.g., through complimentary samples).

6. Accommodate players of all ages, with or without previous exposure to games. Multiple player (cooperative / competitive) games should also be supported.

7. Facilitate the collection of contact information.

8. Provide the means for word-of-mouth advertising (e.g., through social networks).

9. Allow for a high-profile, dynamic presence of the company in exhibition spaces and points of sale.

10. Last less than 2 minutes, so that players do not get tired, those waiting in line do not get bored, and a high throughput of players can be achieved. 
In response to these requirements, and also building upon related work, it was decided to create a Kinect-based PC exergame [16], involving physical activity as a means of interacting with the game. The game would be projected against a large surface, making it highly visible to exhibition visitors. The main reasons for selecting Kinect were that it allows for non-instrumented game control through natural movements, which also afford higher levels of engagement and social behavior [15], performs well under various environmental conditions, and comes at a very low cost. In this respect, it was decided to just use the depth camera's image in order to render a virtual shadow of the players, instead of tracking body skeletons. The rationale was two-fold. On the one hand, it was assumed that it would be easier for people, especially "non gameplayers", to identify with their shadow rather than with an avatar, thus achieving a higher level of control and immersion [22]. On the other hand, this approach allowed for maximum flexibility regarding the number, posture and size of players, as well instantly joining and leaving the game, thus maximizing the opportunities for social interaction [22]. The downside was that people with larger body sizes had a clear advantage, and there was the possibility of accidental "intrusions" in the play area.

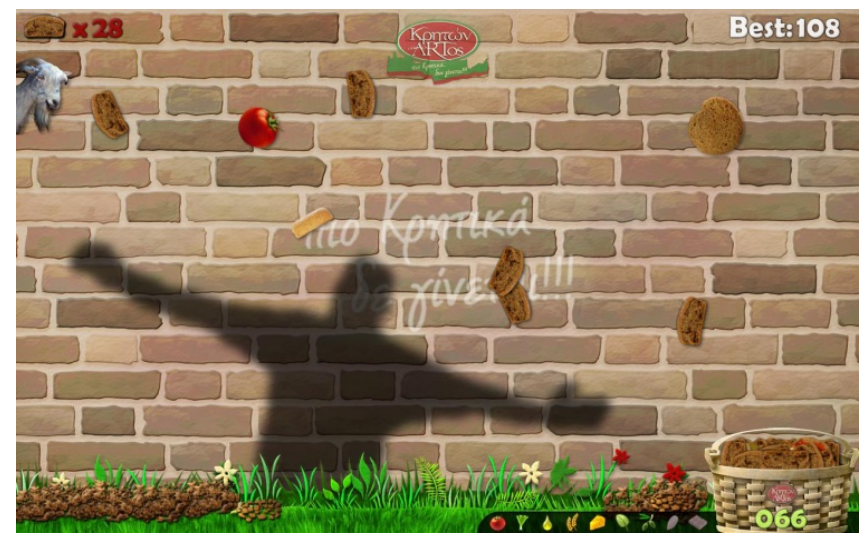

Fig. 1. Screenshot of indicative gameplay

The envisioned gameplay ${ }^{2}$ is simple, straightforward, and has very clear goals [22]. Players perceive their bodies as shadows projected on a brick wall (Figs $1 \& 2$ ). Depending on the players' number, there may be one or two baskets at the two bottom sides of the wall (Fig. 2). A 'rainfall' of rusks starts. Players must use their shadows to put the rusks into their basket. Rusks that fall on the floor are broken into pieces. The game ends when a certain number of rusks have fallen. In order to cater for the aforementioned design goals, the following features were originally included in the game:

1. The company's logo appears on a prominent position on the brick wall and on the player's baskets. Also, its motto (as Cretan as it can get) appears as graffiti on the wall. All in-game graphics are actual photos of the company's products.

2 Videos of indicative play sessions can be found at: http://www. youtube.com/user/icsforthami 
2. When the game starts, a card appears for 5 seconds presenting products and facts about the company.

3. Two musical scores are used combining traditional Cretan music with a modern beat. Additionally, the moves required by the game implicitly refer to traditional Cretan dances. Level selection buttons are Cretan versions of "smilies". The "game over" sign appears as a road sign, which is eventually shot (an infamous practice occasionally performed in the Cretan mainland) and destroyed.

4. If players manage to put together a round rusk and a tomato, a dakos, a popular rusk-based Cretan dish, is created, which provides bonus points if put in a basket.

5. Players receive appropriate, immediate, contextualized feedback $[4 ; 22]$ for all their actions. For example, when an object falls in their basket, a text object popsup illustrating the points won or lost.

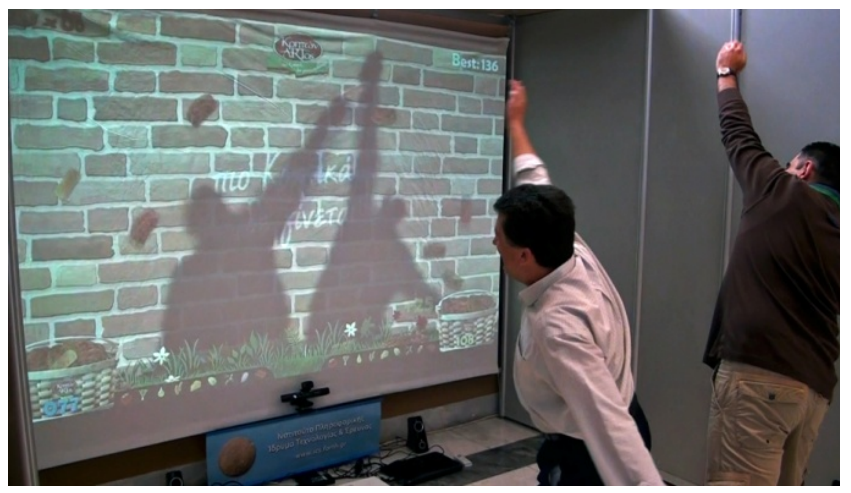

Fig. 2. Playing a two-player competitive game

6. The game requires considerable body movement that increases as time passes. A lot of playtesting has taken place regarding gameplay pace, so that it applies pressure but does not frustrate players [4]. To better match player's skills to game challenge [22], three alternative levels of difficulty have been designed: (a) easy, targeted to small children and older players, (b) hard, for hardcore and returning players and (c) normal, for everyone else.

7. In order to deliberately create a "memorable moment" [13], when the end of the game approaches, a huge amount of rusks suddenly start to fall. To notify players about this event, a bleating goat appears, providing a humorous note, but also another link to Cretan tradition. Additionally, the music shifts to a faster tune.

8. For rewarding players, when a specific score level is reached, a bag of rusks jumps out of the basket, which can then be redeemed with an actual product.

9. During gameplay, at moments that are likely to provoke interesting players' poses the game automatically takes photos of them. Additionally, when the game ends, a photo countdown ("smile moment") appears allowing players to pose. Game graphics, including the company logo, are overlaid to the photos, which are presented on screen when the game finishes and can be sent to the players via e-mail. 
10. Distinct high scores are kept per difficulty level and number of players. If the last game played resulted in a high score, the last photo taken is presented on the game's main screen.

11. As a means to ensure that the total gameplay period will not exceed a maximum time limit, all falling objects come with a lifespan which may vary depending on the level of difficulty, type of object and time of appearance. When an object reaches the last 9 seconds of its "life", it gets a reddish hue (i.e., becomes hot) and a countdown number appears on it.

More than 50 hours of playtesting along with the employment of observational usability assessment methods took place in order to fine-tune the gameplay and also debug the game, in a realistic installation at the premises of ICS-FORTH, with more than 30 players of both genders, with ages ranging from 4 to 52 years old.

\section{$4 \quad$ Installation 1: Syntagma}

The game was installed in an exhibition of traditional Greek food products from the 29th till the 31st of March 2012, in a space located in the central metro station of Athens, at Syntagma Square. The overall setup (Fig. 3) included a 1280x800 shortthrow projector, adjusted on a custom floor stand, capable of producing an image $2.8 \mathrm{~m}$ wide $\mathrm{x} 1.75 \mathrm{~m}$ tall from a distance of $1.8 \mathrm{~m}$. As a means of "hiding" the projector and keeping players from accidentally bumping on it, a small banner was adjusted to an extendable arm, which was fixed upon the projector's stand. A Kinect was mounted on a stand at about $0.5 \mathrm{~m}$ above the floor surface. A red line was stuck on the floor, designating the limits of the play area.

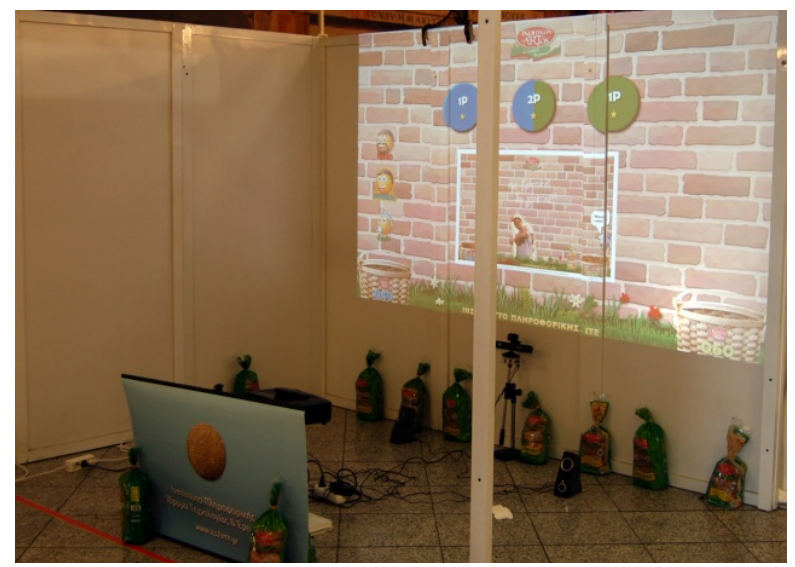

Fig. 3. Game installation at the Syntagma Metro station

In the course of three days, the game ran for a total of 30 hours. It was played 203 times (resulting in the fall of 20.010 virtual rusks) by 173 distinct players (Fig. 4 left), 127 of which were female (73\%) and 46 male $(27 \%)$. Their age ranged from 3 
(four players) to 76 years (Fig. 4 - right). The exact number of players per age range is presented in Table 1 . Seventy-one $(41 \%)$ players stated that they had never played any type of video game before. 136 single-player and 67 two-player sessions took place. In five cases the game was concurrently played by 3 players. The average duration of a game session was 89 seconds.

When asked to provide an e-mail address in order to receive photos that were automatically taken by the game, all 86 people who had one, agreed. Five (elderly) persons said that they did not have an e-mail but said that one of their relatives would contact us in order to receive the photos. No one ever did. Also, it was observed that 9 out of 10 people, without this being a prerequisite in any way (implicitly or explicitly), prior of after playing the game, themselves (or their parents), bought one or more products from the booth.
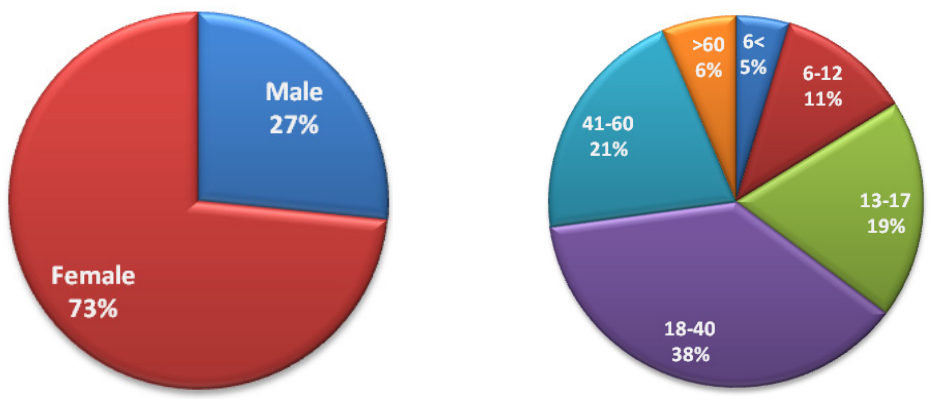

Fig. 4. Installation 1: Player gender (left) and ages (right)

As a means of collecting detailed qualitative data about the game and its impact, a 20 -item questionnaire was created. The first 6 items regarded the players' profile. The 11 next items were statements rated using a Likert scale from 1 to 5 (see Table 2) measuring on the one hand the success of the game and the user experience; while on the other hand the potential impact and usefulness of the game as a marketing tool. Finally, there were 3 open-ended questions. After the first ten failed attempts of interviewing players who were discouraged by the length of the questionnaire, the use of the questionnaire was discontinued. Instead, players were asked to verbalize their opinion about the game, and their answers were recorded. All players stated that they liked the game and that they enjoyed playing it. More than 100 people used words like "fantastic", "great", "very good", or another synonym. Most of the players also thanked us for offering them so much fun and for having a very good time.

After the event, the evaluation questionnaire was posted on-line and a link to it was included to the e-mails with the photos that were sent back to the players. Out of the 86 e-mails sent, 25 recipients answered the questionnaire. 18 of them (72\%) were female and $7(18 \%)$ male (Fig. 5 - left). 13 respondents $(52 \%)$ were 18 to 40 years old and $12(48 \%)$ were 41 to 60 . Also, $13(52 \%)$ were familiar with the food company before playing the game, while $12(48 \%)$ were not. The frequency at which respondents play video games is illustrated in Fig. 5 (right). The aggregate results of the Likert-scale statements are shown in Table 2. Among the things that respondents 
mentioned in the open-ended questions were that they liked: the responsiveness of the game; the (easy) way it was controlled; its high quality; its originality; the fun they got out of it; the fact that their whole family could play it; the music. On the negative side, two respondents wrote that they would like to play more times, or for a longer period, one said that towards the end the game became too difficult for him and another one did not like the music. The "other comments" section mainly included congratulations, statements about the originality of the idea and questions about where and when they could play it again.

Table 1. Installation 1: Number of players per age range

\begin{tabular}{c|cccccc}
\hline Age & $6<$ & $6-12$ & $13-17$ & $18-40$ & $41-60$ & $>60$ \\
Players & 8 & 20 & 33 & 65 & 36 & 11 \\
$\%$ & $5 \%$ & $11 \%$ & $19 \%$ & $38 \%$ & $21 \%$ & $6 \%$ \\
\hline
\end{tabular}
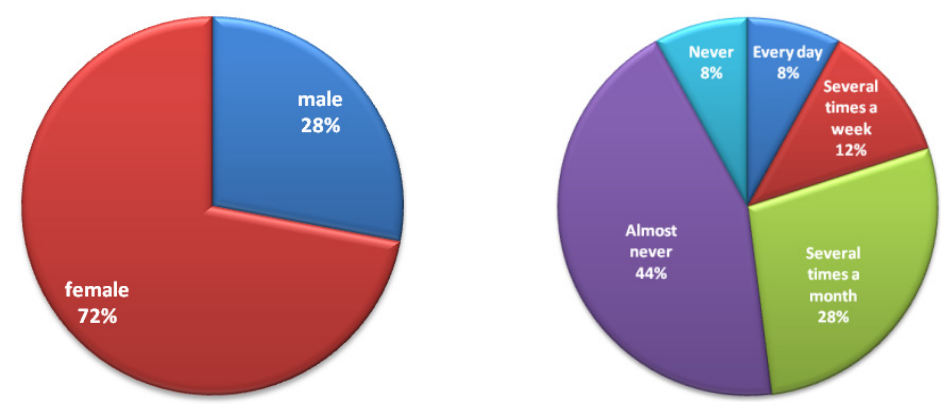

Fig. 5. On-line questionnaire: Player gender (left) and frequency of playing video games (right)

\subsection{What Went Right}

The reaction of all people to the game, including those who played it, their parents and friends, but also bystanders, other exhibitors and people just passing by was $100 \%$ positive. Everyone had a lot of fun and considered it as a very good means for product promotion. The company advertised by the game definitely benefited both in terms of publicity and of highly increased on-the-spot sales. Players of all ages were able to tell the name of the brand and the type of products it makes.

Regardless of the totally uncontrolled installation environment, the game ran astonishingly robustly. There was not a single technical problem (bug, crash, game reaching an undesirable state, loss of recorded data, etc.) during any of the game sessions.

On the first day of the exhibition the game was presented on MEGA (TV) Channel, on the morning show with the highest ratings in Greek television ${ }^{3}$. This day, more than $85 \%$ of the people visiting the booth mentioned viewing the game on TV. The next two days this percentage has fallen to about $60-65 \%$. On the second day, the game also appeared on national television ${ }^{4}$.

3 http://youtu.be/ZkVrtXuotjM

4 http://youtu.be/4vjLYM-3CgU 
Table 2. On-line evaluation questionnaire results

\begin{tabular}{lcc}
\hline Question (1=strongly disagree, 5=strongly agree) & AVG & STD \\
\hline 1. I liked it. & 4.7 & 0.5 \\
2. It was easy to learn how to play. & 4.6 & 0.6 \\
3. It responded correctly and timely to my actions. & 4.2 & 0.9 \\
4. The difficulty level was appropriate for me. & 4.3 & 1.0 \\
5. It was fun. & 4.9 & 0.3 \\
6. The graphics used were of high quality. & 4.3 & 0.7 \\
7. I liked the music. & 4.2 & 1.0 \\
8. It helped me familiarize with the brand "Kriton Artos" & 4.2 & 0.8 \\
$\quad$ and its products. & 4.0 & 0.9 \\
9. It helped me realize that the products of "Kriton Artos" & & \\
$\quad$ are traditional Cretan products. & 4.4 & 0.6 \\
10. It contributed towards creating a positive image about & & \\
$\quad$ "Kriton Artos" and its products. & 4.0 & 0.9 \\
11. It positively affected me towards purchasing products of & & \\
\hline
\end{tabular}

\subsection{What Went Wrong}

For several reasons, almost no one would read the advertising card at the beginning of the game. First, playing instructions game were not included, the time that the card was shown on the screen was usually dedicated to explaining how to play. Additionally, most texts were too long, and also it was too obvious that this part was just a bold advertisement that did not have something to do with the gameplay [7]. The fact that the projector was just a few centimeters in front of the playing area had two disadvantages: (a) there were times where someone had to hold the player back to avoid bumping on it and (b) it prevented shorter children from moving closer to the Kinect and enlarging their "shadow". Also, the idea of hanging the banner from the projector base was (obviously) bad, since whenever someone hit the banner, or there was a sudden breeze, the projector would shiver. Additionally, nobody would read the banner. Thus, it was placed against the booth's wall. Most of the players would try to leave the play area immediately after the "Game Over" sign appeared. Since the last photo was taken after that, we had to orally instruct players to wait for it. The decision to place the photo of the last high scorer on the game's title screen was not very good, since: (a) due to the short life of the event, there were very few returning players; and (b) those who had just played the game were deprived the opportunity to have a last peek at their photo before leaving the play area.

\section{Installation 2: Zappeion}

The game was installed (Fig. 6) at the "Tastes \& Life" exhibition at the Zappeion Exhibition Hall, in Athens, from the 20th till the 22nd of April 2012. Based on previous experience, but also on new requirements of the food company, a number of changes were made to the game setup and software. 


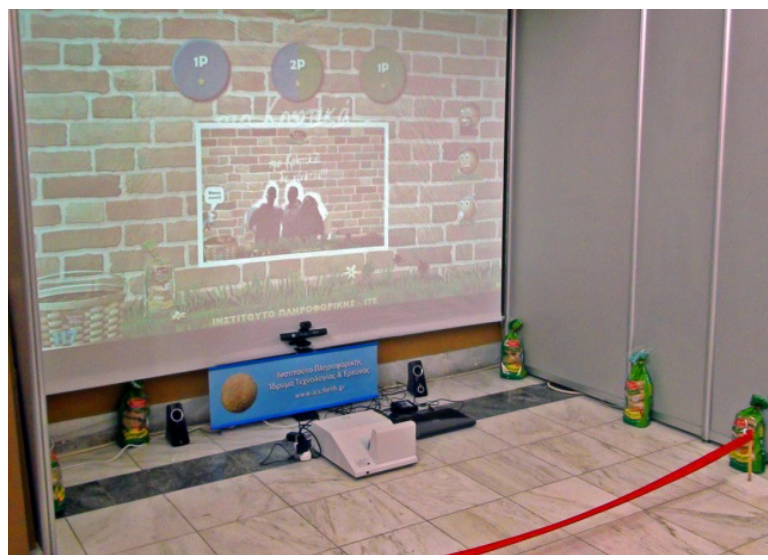

Fig. 6. Game v.2 installation at Zappeion Exhibition Hall

First of all, an ultra-short throw projector was used, which produced the same image size as in the previous installation, with additional brightness, from less than $1 \mathrm{~m}$ distance, thus freeing up valuable space in front of the play area. Also, no projector stand was required, thus simplifying the whole installation. The red tape was replaced by a red ribbon loosely tied on two short free-standing poles, so that if someone stepped on it, it would move along, thus avoiding potential accidents. Additionally, this approach allowed to easily shift the play area closer to the screen whenever needed, e.g., to better accommodate (younger) players. A custom projection screen was fixed against the booth's back side. The banner moved to a much more prominent (and stable) place, underneath the projection screen.

Based on the observations collected during the first installation (see Section 5.3) the following adjustments were made to the game:

- Cards with brief instructions about the game appear at the beginning. The last card is an advertisement that contains just a photo and the name of a product. Since this is the last in a series of cards that the player reads to learn about the game, it is always read before even realizing its purpose.

- The "smile moment" appears prior to the "Game Over" sign.

- When a game finishes, the last photo taken appears on the title screen until a new game starts.

Additionally, the food company wanted to promote a new series of "small bites" rusks coming in nine variations. In order to make players aware of the different flavors, a "small bites bar" was added near each basket. The bar contains grayed out icons symbolizing the 9 flavors. Every time a player collects one of them, the corresponding symbol lights up and a sound effect is heard. Each "small bite" scores 2 points. Additionally, if all 9 flavors are collected a bonus of 25 extra points is gained. 

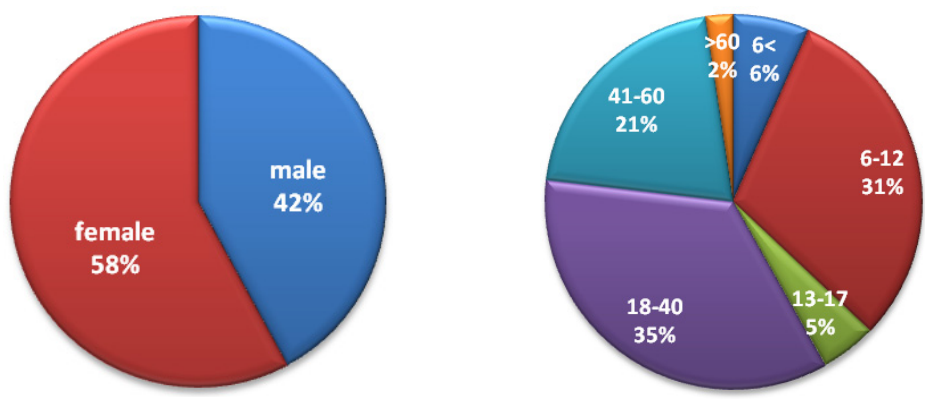

Fig. 7. Installation 2: Player gender (left) and ages (right)

In three days, the game ran for a total of 24 hours. It was played 343 times (resulting in the fall of 23.700 rusks) by 337 distinct players (Fig. 7 - left), 195 of which were female (58\%) and 142 male (42\%). Their age (Fig. 7 - right) ranged from 2 (five players) to 75 years (played against his 70 -year old mate). The youngest player was so short, that she had to stand on a box of rusks in order to appear on the screen. The number of players per age range is presented in Table 3.

Table 3. Installation 2: Number of players per age range

\begin{tabular}{c|cccccc}
\hline Age & $6<$ & $6-12$ & $13-17$ & $18-40$ & $41-60$ & $>60$ \\
Players & 22 & 103 & 16 & 118 & 70 & 8 \\
$\%$ & $7 \%$ & $31 \%$ & $5 \%$ & $35 \%$ & $21 \%$ & $2 \%$ \\
\hline
\end{tabular}

Table 4. On-the-spot questionnaire results

\begin{tabular}{llc}
\hline Question (1=strongly disagree, 5=strongly agree) & AVG & STD \\
\hline 1. I liked it. & 4,63 & 0,54 \\
2. It was easy to learn how to play. & 4,68 & 0,56 \\
3. It was fun. & 4,82 & 0,43 \\
$\begin{array}{l}\text { 4. It helped me familiarize with the brand "Kriton Artos" } \\
\text { and its products. }\end{array}$ & 4,08 & 0,93 \\
5. It contributed towards creating a positive image about & 4,41 & 0,83 \\
$\begin{array}{l}\text { "Kriton Artos" and its products. } \\
\text { 6. It positively affected me towards purchasing products } \\
\text { of "Kriton Artos". }\end{array}$ & 4,1 & 0,87 \\
\hline
\end{tabular}

216 single-player and 127 2-player sessions took place. 39 people won a bag of rusks and 65 achieved to fill in the "small bites bar". The aggregate score of all players was 23.700 . In 20 cases the game was concurrently played by 3 or more players. The maximum number of concurrent players was 6 . In 55 cases children played along with their (grand)parents - sometimes both of them were adults. The average duration of a game session was 101 seconds (due to the newly-introduced game instructions). 165 persons provided their e-mail address to receive the game photos. This time, a much shorter questionnaire was employed. It was briefly presented to the respondents 
who were then left to fill it in by themselves. When the questionnaire was returned, a short informal discussion was often held, aiming to clarify or even verify the selected scores (especially if they were all very high). Of all the people asked to fill it in, only one refused, explaining that she was in a hurry. A total of 100 people responded, 61 female and 39 male (Fig. 8 - left). 66 respondents were 18 to 40 years old, 28 were 41 to 60 and 6 over sixty. 39 were familiar with the company "Kriton Artos" before playing the game while 61 were not. The frequency at which respondents play video games is illustrated in Fig. 8 (right). The aggregate results of the Likert-scale questions are shown in Table 4, while the detailed scores are illustrated in Fig. 9. There were 28 respondents who scored 5/5 all six Likert-scale statements.
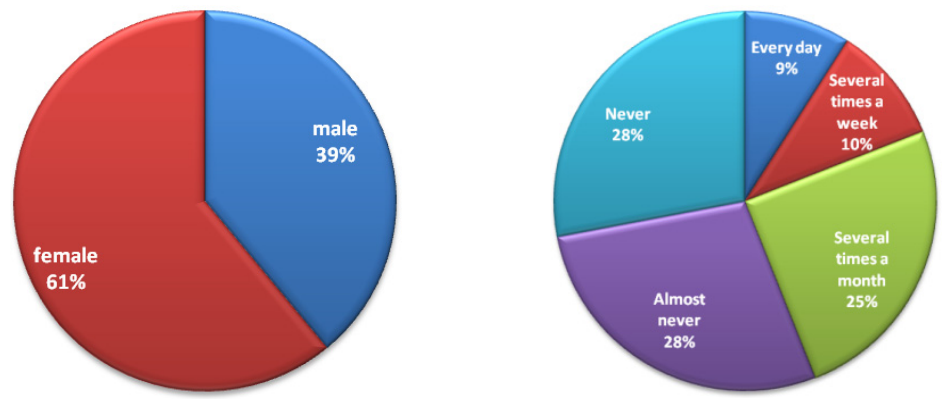

Fig. 8. On-the-spot questionnaire: Player gender (left) and frequency of playing games (right)

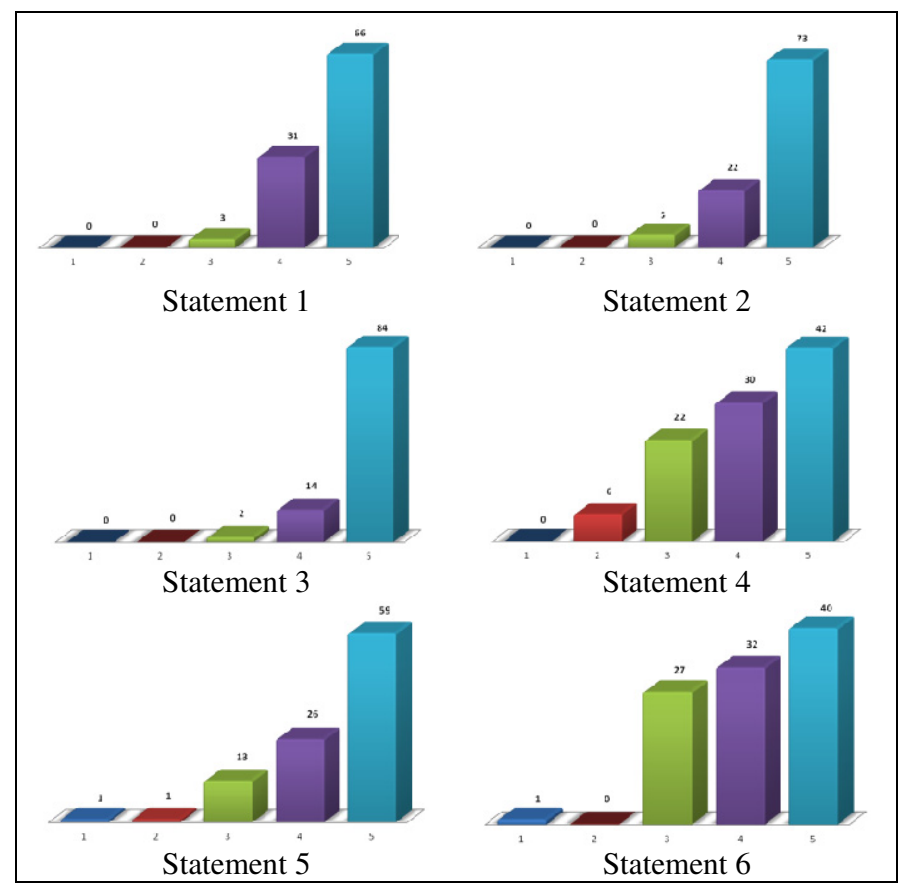

Fig. 9. On-the-spot evaluation questionnaire scores 


\section{Lessons Learnt}

This section summarizes the empirical knowledge gained through the two public installations, analyzing the evaluation questionnaires, as well as observing and discussing with hundreds of players of various ages.

1. Fun rules! People of all ages want to have fun. If you achieve this, they will instantly like you. They will smile at you, thank you, and shake your hand. They will also listen to you, give you their contact data, answer your questions, taste, and most probably, buy whatever you sell.

2. Live bait catches more fish. When there was no one interacting with the game, we had to keep inviting people to come and play. On the contrary, when someone was already playing there would usually be several "volunteers" queuing up very often ones from "unexpected" age groups.

3. Details matter, but not the ones you think. There were several times and reasons that made us thinking about not running the installation at all, because we considered that the quality of the presentation or the overall experience was deteriorated. After asking the players we found out that they did not notice or care about anything of the things that we were so much concerned about. They had fun, the game was working fine, it made them feel good.

4. There will always be surprises waiting for you at the installation site. Even if you think that you have taken every detail into account, be prepared to face lastminute challenges. A bag of tools and a ball of string will come in handy. Design your installation so that it can accommodate dynamically changing environmental variables. Allow for quick and easy adjustment of software parameters that might be affected.

5. Vanity sells (i.e., make it personal). Find a way to put the player's face in the game world. Allow players' to keep and share this image. They will love it. They will give you their contact data without a second thought.

6. Keep it simple, but... The gameplay was extremely simple: "use your shadow to put as many rusks in your basket as you can". Even 2-year old Maria, after playing the game, being all excited about it, would wander around explaining to anyone standing nearby how to play: "Big basket, rusks put in - many many rusks, yeaah!" Still, for people more familiar with video games and returning players, there was another layer of complexity, aiming to provide additional interest and thrill; different types of rusks and combinations would result in higher scores.

7. If the rules can bend, the gameplay will not break. The design decision to use the players' distance from the wall as the game's input mechanism, instead of tracking their bodies, proved to be very successful, since it offered high control flexibility. There were times were 3 or more people would play cooperatively using a single basket, parents carrying their children in their arms, couples hugging or fighting, people holding bags, food, employing various items to augment their reach, extremely short / tall players, children sneaking in a hand, etc.

8. Realism and fun often do not mix well. Initially, a quite realistic and accurate physics model was adopted (e.g., collision among all rusks, bouncing behavior of 
objects). As playtesting revealed, when some of the model's parameters were tweaked (or even totally removed, as in the case of rusk collision) the game was much more fun and "fluid".

9. Boost player success. We knew that most people would play the game just once. Also, a lot of them would not be familiar with video games and we did not want anyone to end the game with very low or no score. Thus, a small number of rusks fall directly in the player's basket. Additionally, in the latest version, in order to increase the possibility of filling in the "small bites bar", only flavors that have not already been collected by the player appear in the game.

10. A thing about adults 18 to 40. Players in this age-range were the ones with the most inhibitions towards playing the game, mainly being afraid of becoming embarrassed in public. Still, there was not a single person who abandoned the game prior to finishing it, or mentioning of having regretted playing it.

11. Full body control (?) Although players were given the hint that the best play posture was keeping both hands spread in the air, the majority used just one hand, probably due to the fact that there are not many real life tasks requiring bimanual interaction. Additionally, about $25 \%$ of the players would place their hands in front of their torso, trying to reach and grab the rusks on the (distant) wall.

12. It ain't over 'til it's over. As explained in more detail in Section 5.3, you should not present anything to the players after the "game over" message.

13. Playtest, playtest and then, playtest some more. The endless hours of playtesting really paid off. To this end, the continuous renewal of our pool of playtesters was crucial, since every person would play the game in a slightly different way, doing, discovering, or saying something new.

14. If you want to collect data, you should do it on the spot. In both installations, $99 \%$ of the people who had an e-mail address instantly gave it away without a second thought in order to receive their photos. In the first installation, only 25 out of the 86 people who received this e-mail responded to the accompanying on-line questionnaire. In the second installation, all people - except just one - who were asked to fill in the questionnaire on-the-spot agreed.

15. Less data is better than no data (i.e., keep it short). People should not spend more time filling in data than actually playing the game.

\section{Conclusions}

The game was indisputably very fun. The related statement in both questionnaires was the one with the highest average rating and the least standard deviation. Additionally, one can safely conclude that the game achieved all its design goals. On the one hand, it offers a highly entertaining experience; on the other hand, it positively contributes to the marketing of "Kriton Artos" company and its products, reinforcing previous research findings $[9 ; 10 ; 12 ; 23 ; 24 ; 25]$. To this end, from the questionnaires and interviews with respondents, it emerges that the game's marketing impact was greater towards people not familiar with the brand, since those already familiar would rather base future purchase decisions on known product quality. Another potential benefit is 
that since the game made a lot of people happy, due to emotional conditioning [10; 23 ] this feeling will subconsciously be associated with the company's products.

A very interesting observation was a significant shift in player behavior and mood. Most people, prior to playing, would speak formally, keeping a distance from the persons running the booth. Afterwards, the majority of them would adopt a much friendlier attitude, being open to discussion, as well as to learning about and tasting the advertised products.

Having conducted several user-based evaluations in the past, one of the concerns regarded the validity of the questionnaires' results which seemed to be considerably (positively) biased. One of the possible explanations for this fact may be the euphoric state in which these players were observed to be after playing the game. Still, the on-line questionnaires which were completed within a time distance from the event reinforce the good results. One may claim that this fact justifies the success of the game as a marketing tool. Also, for the real skeptics (like ourselves) there is a collection of more than 2.000 photos recorded by the game showing people of all ages widely smiling and genuinely having fun.

In conclusion, the overall result proved to be more than just a game. It became a memorable experience for its players, but also for all of us who shared their happiness and excitement. In this respect, probably the best remark was made by a 64 -year old chubby woman working as a cleaning lady, who enthusiastically exclaimed when the game finished: "This is fantastic! It totally makes you forget where you are!"

Acknowledgments. This work has been supported by the FORTH-ICS RTD Programme "Ambient Intelligence and Smart Environments". The authors express their gratitude to Anthony Katzourakis for creating the game graphics and to Haris Kenourgiakis who composed the original musical score. We would also like to thank Mr. Manolis Damianakis and Mr. Giannis Manidakis of "Kriton Artos" for their support towards realizing the public installations.

\section{References}

1. Csikszentmihalyi, M.: Flow: The psychology of optimal experience. Harper Collins, New York (1990)

2. Cowley, B., Charles, D., Black, M., Hickey, R.: Toward an understanding of flow in video games. Comput. Entertain. 6(2), Article 20 (2008)

3. Dahl, S., Eagle, L., Baez, C.: Analyzing advergames: active diversions or actually deception. An exploratory study of online advergames content. Young Consumers 10(1), 46 (2009)

4. Desurvire, H., Caplan, M., Toth, J.A.: Using heuristics to evaluate the playability of games. In: CHI 2004 Extended Abstracts, pp. 1509-1512 (2004)

5. eMarketer With Rise of Social, There's a Game for Any Marketer (2011), http: / /www. emarketer.com/Article.aspx?R=1008652 (retrieved November 21, 2011)

6. eventology Goodyear Virtual Pits 3D (2008), http: / /www . eventologyglobal . com/ proyectos_eng.php (retrieved October 22, 2011) 
7. Friestad, M., Wright, P.: The persuasion knowledge model: How people cope with persuasion attempts. Journal of Consumer Research 21(1), 1-31 (1994)

8. Grace, L.D., Coyle, J.: Player performance and in game advertising retention. In: Proc. of ACE 2011, Article 55 (2011)

9. Gross, M.L.: Advergames and the effects of game-product congruity. Comput. Hum. Behav. 26(6), 1259-1265 (2010)

10. Gurau, C.: The Influence of Advergames on Players' Behaviour: An Experimental Study. Electronic Markets 18(2), 106-116 (2008)

11. iLogic: BMW 1 Series: Projection Mapping Racing Game (2012), http://www.ilogic.co.za/interactive-projection-campaigncase-study (retrieved February 10, 2012)

12. Ip, B.: Product placement in interactive games. In: Proc. of ACE 2009, pp. 89-97 (2009)

13. Jenkins, H.: Game Design as Narrative Architecture. In: Harrington, P., Frup-Waldrop, N. (eds.) First Person, pp. 118-130. MIT Press, Cambridge (2002)

14. Lee, M., Faber, R.J.: Effects of product placement in on-line games on brand memory. Journal of Advertising 36(4), 75-90 (2007)

15. Lindley, S.E., Le Couteur, J., Berthouze, N.L.: Stirring up experience through movement in game play: effects on engagement and social behaviour. In: Proc. of CHI 2008, pp. 511-514 (2008)

16. Mueller, F., Agamanolis, S., Picard, R.: Exertion Interfaces: Sports over a Distance for Social Bonding. In: Proc. of CHI 2003, pp. 561-568 (2003)

17. O'Green, J.: Top things NOT to do in advergaming (2008), http: / / www. imediaconnection.com/content/18067.asp (retrieved December 6, 2011)

18. Peters, S., Leshner, G., Bolls, P., Wise, K.: Get in the Game: The effects of advergames on game players' processing of embedded brands. In: Proc. of International Communication Association (2009), http: / citation.allacademic.com//meta/

p_mla_apa_research_citation/3/0/1/1/2/pages301128/

p301128-1.php (retrieved November 21, 2011)

19. Rohrl, D. (ed.): 2008-2009 Casual Games White Paper (2009), http://wiki.igda.org/Casual_Games_SIG\#White_Papers (retrieved December 6, 2011)

20. Sherry, J.L.: Flow and media enjoyment. Communication Theory 14(4), 328-347 (2004)

21. SiA Interactive: Coca-Cola Virtual Penalty Kicks (2007), http: / / www.siasistemas.com/sitio2/eng-050753.html (retrieved October 22, 2011)

22. Sweetser, P., Wyeth, P.: GameFlow: a model for evaluating player enjoyment in games. Computers in Entertainment 3(3), 1-24 (2005)

23. Waiguny, M.K.J., Nelson, M.R., Terlutter, R.: Entertainment matters! The relationship between challenge and persuasiveness of an advergame for children. Journal of Marketing Communications 18(1), 69-89 (2012)

24. Winkler, T., Buckner, K.: Receptiveness of gamers to embedded brand messages in advergames: Attitude toward product placement. Journal of Interactive Advertising 7(1), 37-46 (2006)

25. Wise, K., Bolls, P.D., Kim, H., Venkataraman, A., Meyer, R.: Enjoyment of advergames and brand attitudes: The impact of thematic relevance. Journal of Interactive Advertising 9(1), 14 (Fall 2008) 